\title{
Effects of System Management on Value Creation and Global Growth in Born Startups: Focusing on Born Startups in Korea
}

\author{
Rok Lee ${ }^{1}\left(\mathbb{D}\right.$, Ju Gyeong Park ${ }^{2, * \mathbb{D}}$ and Sung Hyeon Park ${ }^{2} \mathbb{D}$ \\ 1 Research and Development, EMS, Jinju 52811, Korea; lsbems@hanyang.ac.kr \\ 2 Department of Business and Administration, Graduate School of Hanyang University, Seoul 04763, Korea; \\ shpark21@hanyang.ac.kr \\ * Correspondence: jgpark1@hanyang.ac.kr; Tel.: +82-10-4250-2614
}

Received: 16 January 2020; Accepted: 3 March 2020; Published: 7 March 2020

check for updates

\begin{abstract}
This study is intended to determine the effects of system management on value creation and global growth in born startups. To achieve this, a survey was empirically carried out on 300 owners in born startups with less than five years' experience. The findings are as follows. First, entrepreneurship, operation system, and support system as sub-variables of system management have a positive effect on value creation. Second, entrepreneurship and operating system have no significant effect on global growth, but the support system has a significant effect on global growth. Third, value creation has no significant mediating effect on global growth, which means that owners' entrepreneurship can boost value creation as a corporate systematic operation when they have globally-oriented thinking, relationships through global network organization, the expertise of business, and some level of capital. In particular, their capability and expertise can be drivers to enter early global growth companies through value creation. Consequently, for the early value creation and global growth of born startups, they should recognize that system operation and value creation-oriented corporate global experience, due to their entrepreneurship as international companies under global market orientation, are key variables affecting a global born startup, and thus reflect them in management.
\end{abstract}

Keywords: born startup; system management; value creation; global growth

\section{Introduction}

A born startup is a startup company that has innovative technologies and ideas originated in the U.S. Silicon Valley but is largely dependent on external capital investments due to its small size and lack of capital financing, meaning an international company settled in the short period of 3 to 5 years [1]. This concept of born startup has recently become a new driving force for growth and job creation based on high technology and economies of scale.

In particular, the production and employment growth rates of the high-tech industry centered on born startups have been well ahead of other industries and driving economic growth since the global financial crisis. The representative industry includes born startups in seven fields, namely, computer manufacturing; electronic shopping; software publishing; data processing, hosting and related services; internet publishing, broadcasting, and web search portals; computer systems design; and scientific research and development services. This is attributed to the fact that between 2010 and 2015 , employment in these industries increased to $20.3 \%$, greatly overtaking the whole private sector (11.1\%) [2], and from 2005 to 2013, production in the $27 \mathrm{EU}$ countries remained at a similar level, while production in born startups rose to $26 \%$ during the same period [3]. 
With regard to this, Decker et al. [4] observed that approximately $50 \%$ of newly created employment in the United States came from young high-growth firms with an employment growth rate of more than an annual average of $25 \%$, of which most of these companies were born startups.

This depicts the fact that the born startup ecosystem of the U.S. is growing rapidly in high technology sectors, and global private investment in these born startups has increased nearly 3.6 times over the last five years, from USD 45.3 billion in 2012 to USD 164.4 billion in 2017, thereby supporting the growth engine [5].

The rapidly-growing global born startups generally have characteristics different from those of companies that have entered the international market, which achieve internationalization at high speed, within 2-3 years, when compared with general entry into the international market [1]. They have the characteristics of being more competitive by conducting profit activities in the international market immediately after startup [6-8], have the merit of high growth potential, and look forward to a driver of bigger profit growth rate in the international market than they would in the domestic market. In other words, global market orientation, owner's marketing capability, orientation to an international company, and global experience of a company as factors of early value creation and growth for born startups are emerging as major variables affecting global born startups.

As for the earlier preceding studies, however, Kuivalainen et al. [9] and Knight and Cavusgil [10] stated the strategies required for companies to enter the global market in a study of Finnish companies. They said that market distance, export turnover, and internationalization time, suggested by the former, and an aggressive marketing strategy and internationalization orientation with priority to overseas target markets, suggested by the latter, are a distinction for various global startups.

Oviatt and McDougall [11] set forth the difference between traditional global companies and international newborn startups as follows. First, existing traditional companies give priority to entry into internationalization over global entry by overseas direct investment; however, born startups seek global entry by strategic alliance. Second, traditional companies place global entry as security for their success in the country; however, born startups use a strategy of infusing raw materials/subsidiary materials, human resources, funds, and time to target the global market from the beginning of entrepreneurship. Third, born startups have a distinct difference in that they have a much faster global occurrence time than traditional companies do.

In this way, global born startups should be supported by many strategic factors before they are settled as born startups in a short period of time, but existing previous studies are only concerned with support factors of most startups [12-16]. The study-which approaches how to figure out the demand strategies before general startups are settled as born startups in a short period in the global market-is very limited [17-19]. In particular, this study, which seeks to find the key driving force for the early global growth of born startups, will have very timely usefulness by comparing the difference between high-growth startups in cities of countries where the competition between born startups comes via countries or global time. Accordingly, it aims to identify the following research tasks with the purpose of determining the effects of entrepreneurship, operation system, and support system as system management on value creation and global growth, and the relationships between these factors, targeting managers of successful startups in Korea settled as born startups in a short period of time among global startups. First, how does system management affect value creation in born startups? Second, how does system management affect global growth in born startups? Third, how does value creation through system management affect global growth in born startups?

\section{Literature Review}

\subsection{System Management in Born Startups}

A born startup is a new-venture company leveraging innovative technologies and ideas related to new technology-based high-risk and high-profit areas, requiring external capital investment (e.g., accelerators, angels, and unicorns) and successfully settling within 3 to 5 years. Being "global born" 
means that the startup enters overseas markets during its early stages of establishment. Thus, they utilize the resources and networks of overseas markets to enter markets quickly and generate higher profits. The representative variables of the system management factors for these global companies are divided into entrepreneurship, corporate operation systems, and support policies. These sub-variables are further subdivided as follows.

\subsubsection{Entrepreneurship}

It can be said that managers who lead the organization change themselves to create new value with a spirit of innovation together with the members of the organization and try to make an opportunity for success by responding to external change and using the change as a stepping stone. This kind of entrepreneurship can be applied to a wide range of subjects and situations. The entrepreneurial management is a "comprehensive practice management" that includes thinking and behavior. These entrepreneurs can be defined as "people who take the lead in creative destruction through innovation" for entrepreneurship. Organizations can also sustain their companies in the long term when they create the conditions under which entrepreneurship can be continuously maintained at a high level [20]. Schumpeter defined entrepreneurs as "people who take the lead in creative destruction through innovation," and said that creating an environment to sustain entrepreneurship is more important than anything else [21].

Meanwhile, among the factors required for entrepreneurs affecting corporate performance, global orientation generates company-wide market information reflecting the demands of current and future customers as the focus shifts from the perspective of core technology within the company and customer to the market-oriented perspective in performing corporate management strategies. It is a capability that requires accurate utilization of market information created by spreading the generated market information throughout the company [22]. In particular, business owners' orientation toward the global market is an opportunity for companies to actively collect foreign information, design products for the global market, and reflect their characteristics from a global perspective in decision-making [23]. These managers have different global orientations, and their differences greatly affect the behavior of exports and the performance of companies. Moen [6] supported this in a study of 15 company managers out of 17 companies, showing that their commitment to exports is significantly related to export performance, and said that companies with managers who have a global orientation are likely to become global companies [24].

In addition, the global orientation of the owner's entrepreneurship narrows the culture and psychological distance of the overseas market areas through the manager's overseas work experience and transforms the company's international activity perspective more proactively into an internationally oriented company. This comes from the manager's will that global orientation drives corporate members to create global value by aligning with global goals and moving forward consistently, but it is important as a system factor [7].

\subsubsection{Operation System}

The corporate operation system is the behavior and decision-making to pursue and develop innovative services that can be differentiated from other companies in the market [25]. This is an effort to continue to pursue new market opportunities, improve current businesses, and expand the areas [6]. The corporate operation system refers to an entrepreneurial process of how to establish a company [26].

The previous studies have shown that this was the behavior that creates valuable organizational capabilities by seeking opportunities despite the lack of resources within the company [27], which can be defined as the decision-making and execution process for developing and providing innovative services from a strategic perspective [25]. In other words, the systematization of internal organization within a company is a variable that includes the product, marketing, and professional human resources in system operation [25]. The convergence and systematization among these variables are very important for early settlement and stabilization of global startups. 


\subsubsection{Government Support System for Startups}

The government support policy of startups provides a system for education, training, and comprehensive startup as well as capital [28], in which the key factors include the network of related fields, startup potential, differentiated idea, space, and capital $[3,27,29]$. National policy is a major environmental factor for companies, as it is important in determining whether an investment in technology and knowledge of any industry will lead to maximum compensation [30]. The government policy covers government regulations and controls, government enforcement policies, and various support programs, in which the national institutional policy direction includes government enforcement policies, regulations, and programs to support startups [25]. While the government is making laws, regulations, rules, and policies with public institutions to support startups, private institutions include requirements for culture, morality, belief, and government policy of startup [31].

Factors affecting startups include corporate activity level, national per capita income, and economic growth rate, in which there is a significant relationship between them [31]. In addition, the economic stability of startups $[3,6]$ and the capital availability of startups [4] are major factors.

\subsection{Value Creation and Global Growth Strategy of Born Startups}

The ecosystem creation and support of born startups is a global trend in which born startups with the possibility of high growth and high profits are becoming more and more popular in national economies.

Recently, startups are characterized by the creation of high value-added products through the convergence of industries and technologies in accordance with the advent of the Fourth Industrial Revolution. As the world-famous unicorn born startups, led by Silicon Valley in the United States, have been steadily produced, they have become the economic growth engines of major countries [5].

The economic impact of startups can be measured in terms of their ecosystem value. Ecosystem value in this context refers to newborn growth companies that create high added value in the global competitive environment through new technology innovation and convergence. These startups represent the world's innovative growth companies, which are generally concentrated in Silicon Valley and venture towns of major cities around the world.

Silicon Valley accounts for $1.2 \%$ of the California area, $7.8 \%$ of the California population, $10.4 \%$ of the California GDP, and $9.6 \%$ of the California jobs, but labor productivity in Silicon Valley has risen by $31.3 \%$ in 15 years, showing steep growth (by 2017, overall labor productivity in the U.S. was $19.3 \%$ ).

Currently, the born startup ecosystem is rapidly expanding in developed countries such as the U.S. and Europe. According to the 2017 Global Startup Ecosystem Report published by the U.S. Born Startup Genome Project [12], major cities of the U.S. (e.g., Silicon Valley, New York, Boston) and Europe (e.g., London, Berlin, Paris, Stockholm) dominated the top 20 global startup ecosystems.

The value creation breakdown and global growth strategies by the region are as follows.

\subsubsection{North America}

Silicon Valley: It has the world's best capital, talent, and investors, and has strengths in the fields such as artificial intelligence (AI), big data, fintech, and biotech. Investment and sales strategies are active in the biotech field, with $25 \%$ of the world's venture investment coming from Silicon Valley. As of 2017, the ecosystem value of startups reached USD 264 billion, showing an overwhelming difference.

New York: It is the world's second-largest startup city in which major technologies and industries in the leading field are expanding the global market with strengths in advanced manufacturing and robotics such as cyber security, bio/health and 3D printing. As shown in Figure 1, the ecosystem value of startups ranks third with USD 71 billion after Silicon Valley and Beijing. 


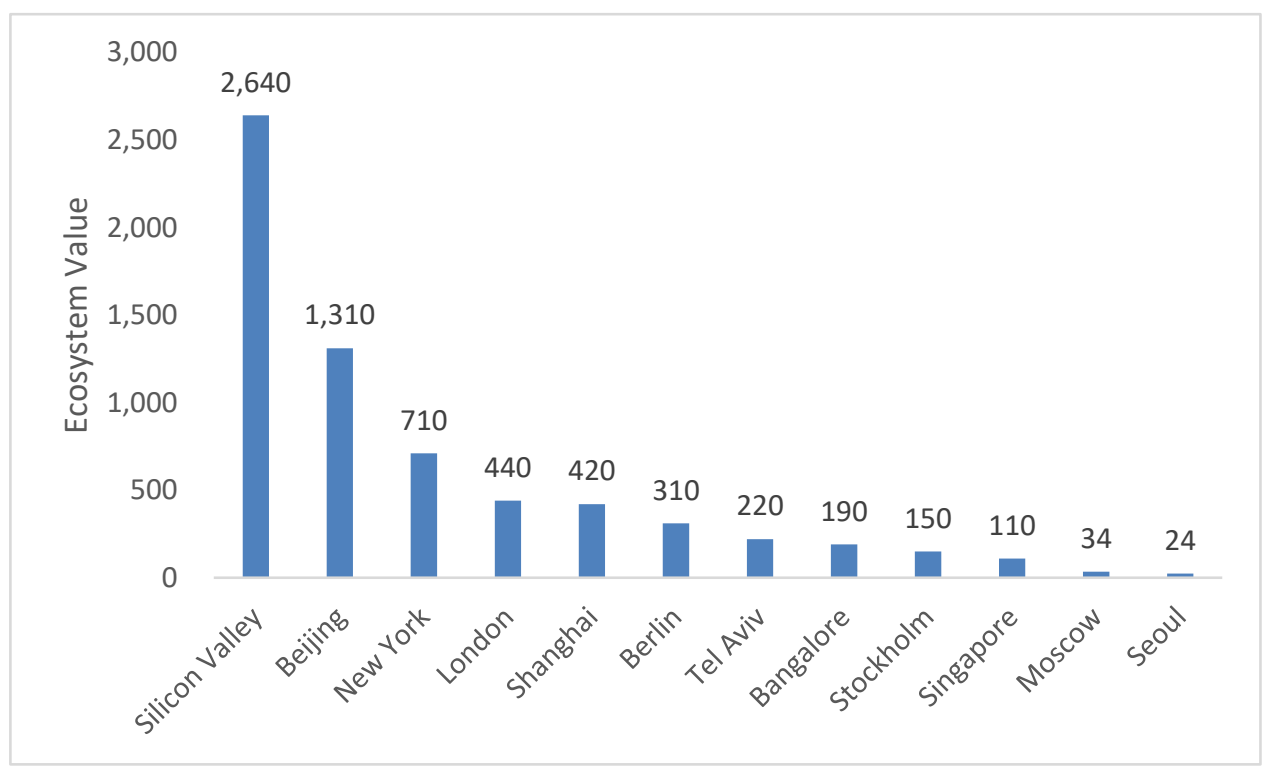

Figure 1. Regional startup ecosystem value [10].

\subsubsection{Europe and the Middle East}

London: It is bringing about the best results of European startup ecosystems, driving the growth of the European digital economy, and is forming a great part of the economy, with more than 80,000 jobs in the region. The ecosystem value of startups in London is fourth globally, with USD 44 billion.

Paris: President Macron has decided to invest USD 11 billion in Paris to make France the "country of unicorns" and has been actively implementing startup support policies such as La French Tech. It has strengths in fields such as edutech, fintech, and bio/health.

Tel Aviv: It has the largest number of startups per person in the world, fueled by government-led innovation policy, and has strengths in fields such as cybersecurity and autonomous cars. As dependence on software and information technology is growing in the autonomous car field, Tel Aviv is emerging as the center of the world's autotech field, with a triple-increase in investment over the past three years. The ecosystem value of startups in Tel Aviv is 7th, with USD 22 billion.

\subsubsection{Asia}

Beijing: In 2017, the total venture investment in China was USD 40 billion. Currently, it has 40 unicorns, and it has strengths in fields such as AI, big data, edutech, and blockchain. In the AI field, it is developing an area that can attract nearly 400 companies, led by the government. The startup value stands at USD 131 billion after Silicon Valley, ranking second overall.

Hong Kong: It is highly accessible in terms of talent, technology, and resource supply, in close proximity to Shenzhen, China, and has strengths in fields such as fintech, bio/health, and IoT consumer electronics.

Singapore: The government-led startup support policy, including R\&D expenditure of $1 \%$ of GDP, is active. It has strengths in the fields of fintech, digital media, and big data. The startup value is 10th, with USD 11 billion.

Korea: Startups in Korea are growing very rapidly but are still far below the global startup ecosystems such as Silicon Valley, London, and Singapore. The startup value stands at USD 2.4 billion, ranking 12th overall.

Overall, a recent Global Startup Ecosystem ranking showed that Silicon Valley, New York, and London were ranked 1st, 2nd, and 3rd, respectively. Beijing (4th), Shanghai (8th), and Stockholm (14th) were included in the new ranking, while Seoul was not ranked in the top 20, reflecting the limit [10]. Figure 1 illustrates a comparison of Seoul with other selected major cities ranked in that study. 
Meanwhile, in connection with external ecosystems, domestic and foreign startups are important not only for getting mentoring or investment for the early stage of growth but also for scaling-up afterwards. The Waterloo Startup Ecosystem Report [12] showed that startups aimed at overseas consumers from the initial stage grew 2.1 times faster than non-startups.

\subsection{Competitive Strategy and the Growth Engine of Global Born Startups}

\subsubsection{Global Startup Investment Scale}

Since startups have the inherent characteristics of high risk and high growth, it is important to create an environment where promising startups can be invested in in a timely manner.

Currently, global private investment in startups worldwide has risen 3.6 times from USD 45.3 billion in 2012 to USD 164.4 billion in 2017. In particular, thanks to the rapid progress of startups in China, the center of global startups is moving quickly from North America to Asia [32].

Startups have a particularly high-risk and high-growth nature in that they start from the beginning with the aim of scale expansion and world market entry, unlike the conventional smalland medium-sized companies which do not significantly expand their scale after business startup. Paul Graham, co-founder of the famous accelerator Y Combinator emphasized, "making startups into startups is only growth; not the fact that they started a new business, or that they were funded by venture capital", suggesting the importance of this [33].

\subsubsection{Growth Engine of Global Born Startups}

Silicon Valley, which focuses on AI technology as a future innovation engine, is preemptively promoting the AI startup ecosystem, including investment in AI startups and expansion of mergers and acquisitions, strengthening of industry-university cooperation, and improvement in data accessibility.

Amidst China's rapid ascent, a virtuous circle (investment $\rightarrow$ startup growth $\rightarrow$ investment fund recovery $\rightarrow$ reinvestment) between global IT companies and startups in Silicon Valley provides a foothold for continued competitive advantage in the AI field. To preoccupy the competitive advantage of AI that emerged as a future core technology, Silicon Valley is leading the global market by rapidly promoting research and industrialization from source technology to application service development.

As the AI technology in the introduction stage develops into the commercialization stage, it is expected that the industrial structure will be reorganized and the new market will be opened through technology innovation. The global market size of AI is expected to reach USD 52.2 billion in 2021 from USD 7.81 billion in 2016, according to an IDC [34] report.

In particular, the U.S. is dominating rival countries, ranking first in all aspects such as the number of most influential AI researchers, the top-level AI research and special research papers, AI research capability, technology level, and investment amounts [35].

Simultaneously, as China is actively investing in AI technology; it is emerging as a competitor of a two-way race with the U.S. There is a prospect that China will overtake the U.S. in the future as its AI capacity is rapidly being strengthened [36].

The Chinese government is leading the development of AI technology, with the aim of fostering a market of 1 trillion yuan (about 180 trillion won) in the AI core industry and 10 trillion yuan in related industries by 2030 .

At present, the AI technology capacity of the U.S. is twice that of China because its competitive advantage is expected to remain for a while. Here, China holds a dominant position only in "data" of the four fields: "hardware," "data," "algorithm,", and "commercialization." It is known to fall significantly behind the U.S. in the remaining three fields. In the field of AI hardware, the U.S. accounts for half of the world market in terms of semiconductor production and investment in manufacturing enterprises, overtaking China with a one-digit market share. 


\subsubsection{Survival Rate of the Global Born Startup}

Technology-based startups have contributed to the increase in the number of high-tech companies worldwide, rising $47 \%$ from 116,000 in 2007 to 171,000 in 2016. During the same period, the number of companies having more than 10 years' experience jumped $40 \%$, indicating that the participation and growth rate of technology-based startups has remained high. The survival rate of technology-based startups is somewhat lower than that of general startups. The 5-year survival rate $(41 \%)$ of technology-based startups was lower than that of general startups (48.2\%). From 1998 to 2015, $78 \%$ of technology-based startups survived more than 1 year, of which only $41 \%$ survived longer than 5 years.

\subsubsection{Wage Scale and Industry Weight}

Technology-based startups maintain high pay levels compared with small-scale employment. Although technology-based startups accounted for only $2.8 \%$ and $1.2 \%$ of the U.S. companies and workers, respectively, they accounted for $2.7 \%$ of the entire U.S. wage pool. Sixty percent of job growth in born startups comprised the majority of technology-based startups, which created 1.2, 1.1, and $1.5 \mathrm{M}$ jobs in 2007, 2011, and 2016, respectively. This is a $25 \%$ rise in jobs over the past decade. During the same period, the number of jobs in companies having more than 10 years' employment rose $9 \%$ from 2.8 (2007) to $3 \mathrm{M}$ (2016). The percentage of technology-based startup workers in the high-tech industry rose from $31 \%$ to $33 \%$. The percentage of startup workers was only $19 \%$ in the entire U.S. economy, and the percentage of technology-based startup workers in the high-tech industry was 33\% (2016).

The job growth of technology-based startups was more than twice as much as that of general startups. Ian Hathaway at the Kauffman Foundation [37] analyzed the job growth effect for technology-based startups in 14 industries from 1990 to 2011.

(1st- to 5th-year startups) The employment growth rate of technology-based startups (12\%) was twice that of general startups (6\%) (6th to 10th-year startups). The employment growth rate of technology-based startups tripled from that of general startups, and the effect of technology-based startups on other industrial jobs was very significant. According to an analysis by economist Enrico Moretti [38], five additional jobs were created in other industries for every one job created in technology-based startups.

As a result of the wage contribution of technology-based startups, the annual salary of technology-based startups was 2.13 times higher than the U.S. average and 2.76 times that of general startups. When compared with the entire industry, the annual salary of technology-based startups in 2016 was $\$ 102,000,2.13$ times the U.S. average annual salary of $\$ 48,000$.

The job and wage status of the top five high-tech industries showed that job creation and wage growth were prominent in the computer system design services industry, computer and electronics manufacturing, research and development, pharmaceuticals, and semiconductor machinery, among the top 10 technology-based sub-industries.

The number of startups in the computer system design industry rose to $56 \%$ from 48,000 in 2007 to 75,000 in 2016 . The employment of startups in the computer system design industry rose to $28 \%$ over the past 10 years, from 340,000 to 440,000 . By 2016, startups in the computer system design industry were close to the average annual salary (i.e., $\$ 100,000$ ) of the computer system design industry with an average annual salary of $\$ 99,000$. Wages in the top five high-tech industries were relatively high.

\section{Methods}

\subsection{Research Model and Hypothesis}

\subsubsection{Research Model}

The factors, which in system management in global startups affect the global growth, vary from a research perspective. It is not enough to explain the corporate performance of conventional companies 
by technology, entrepreneurship, and culture in global startups, and external factors such as network and policy support are important.

This study attempts to examine the effects of the support and operation systems supported by the government on value creation and global growth, according to entrepreneurship, which is a key factor of global startups.

Zahra et al. and others evaluated internationalizing companies as global born startups within three to six years after venture startup [24].

In addition, other studies are based on the performance of value creation, emphasizing the perception of the management and managers as one of the performances of global startups. Knight [10] measured the performance of international markets as the performance of products such as market share, sales growth rate, and pre-tax profitability to use them in research.

Based on this, this study will also set up and apply the model as shown in Figure 2. In terms of independent variables, first, (1) global orientation, (2) network capability, (3) owner's expertise, and (4) capital scale were selected as sub-factors of entrepreneurship. Second, (1) product competitiveness, (2) marketing capability, (3) professional human resources, and (4) system operating capability were selected as sub-factors of the operating system. Third, (1) commercialization support, (2) operation fund support, (3) technical support, and (4) facility support were selected as factors of the support system. Global growth and value creation were selected as a dependent variable and a parameter, respectively $[10,39]$.

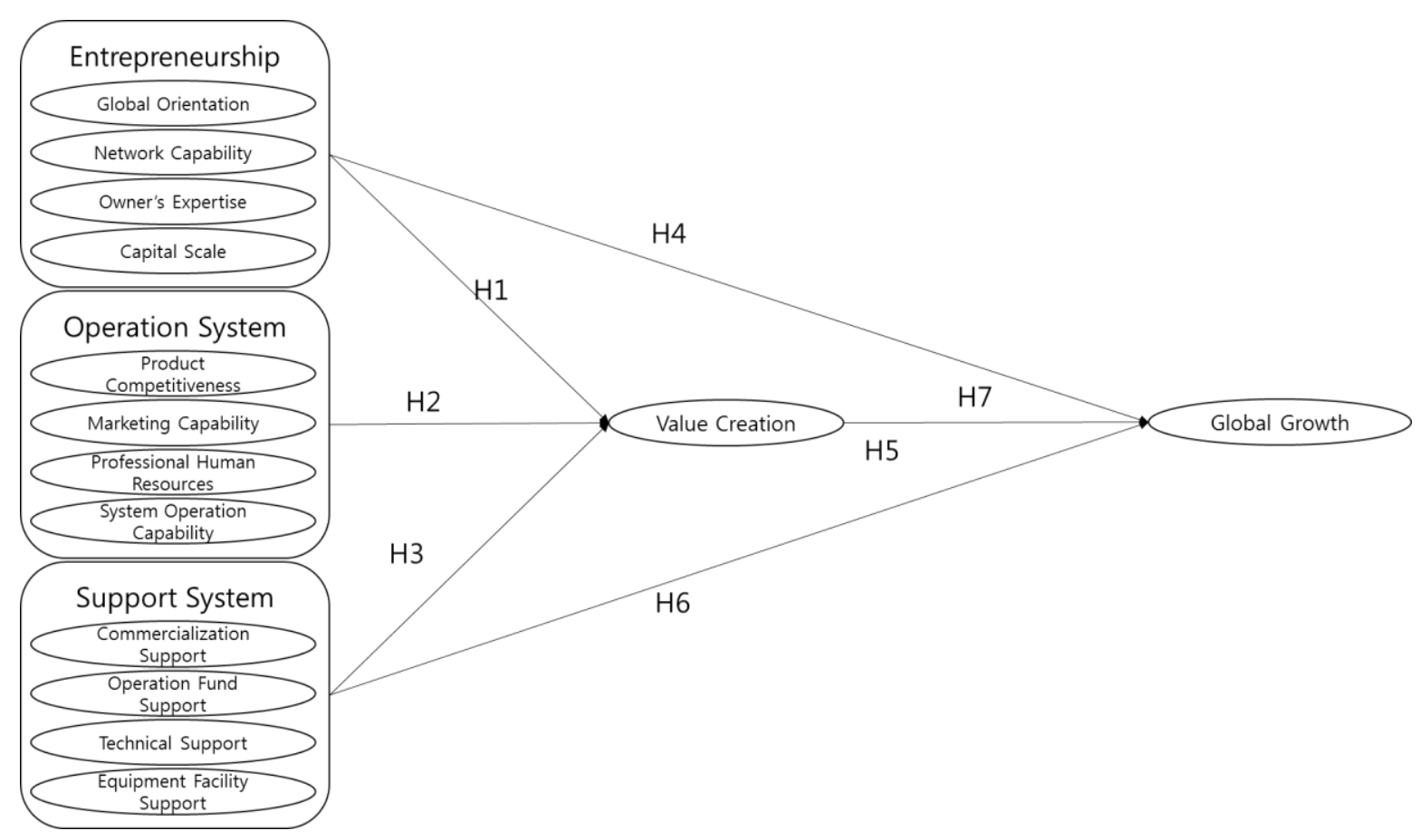

Figure 2. Research model.

\subsubsection{Hypothesis Establishment}

The entrepreneurship, organizational operation, and support system are a collection of internal and external resources that can be utilized by entrepreneurs in startups or venture companies, such as institutional support and operating system, in a theoretical approach based on resource dependence. In this study, the external environmental resources in the process, using which entrepreneurs perform entrepreneurship, play an important role in the growth of venture companies [21]. According to the resource-based theory, external support and operation system environments have a significant effect on entrepreneurship and corporate management value creation and growth [31]. External environmental 
resources affecting entrepreneurship include venture capital system, industrial policy support of friendly governments, presence of experienced entrepreneurial manager market, characteristics of industrial structure, abundance of internal operation environment, the existence of incubator organization and accessibility. Research on these resources was discussed with a focus on improving corporate value creation [21]. Therefore, based on this discussion, the hypotheses were set as follows.

Hypotheses 1. Entrepreneurship in born startups will have a positive effect on value creation.

Hypotheses 2. Operation System in born startups will have a positive effect on value creation.

Hypotheses 3. Support System in born startups will have a positive effect on value creation.

Zahra [24] hypothesized that entrepreneurship, which is evaluated as initiative, innovation, and risk sensitivity, affects the corporate global growth that is evaluated as profitability and growth potential, indicating that there is a significant positive effect between founder's entrepreneurship and corporate global growth [40]. Entrepreneurship leads to a synergistic effect when institutionalized through the combination of an internal operating system and an external support system, thereby affecting global growth. This association was asserted by stating that the direct effects of increased sales and indirect effects of support of facilities and environmental factors in the market are also factors that have a greater impact on the company's management growth. [41]. Therefore, this study hypothesizes that the operating and support systems, as well as entrepreneurship, will have a positive effect on global growth, setting the following hypothesis.

Hypotheses 4. Entrepreneurship will have a positive effect on global growth.

Hypotheses 5. Operation system will have a positive effect on global growth.

Hypotheses 6. Support system will have a positive effect on global growth.

Hypotheses 7. Value creation will have a positive effect on global growth.

\subsubsection{Questionnaire Composition}

Based on the data of Moon Byung-ki [13] and Kim Kun-woo [18] and the precedent study of North [30], the tool for measuring this survey was composed of a Likert 5-point scale as a response to the questionnaire and 26 items as shown in Table 1 to examine the effects of system management on value creation and global growth in born startups.

Table 1. Questionnaire composition.

\begin{tabular}{|c|c|c|c|c|c|}
\hline Classification & Factor & Item Number & $\begin{array}{l}\text { Number of } \\
\text { Questions }\end{array}$ & Scale & Source \\
\hline \multirow{3}{*}{$\begin{array}{l}\text { Independent } \\
\text { Variable }\end{array}$} & Entrepreneurship & $1-4$ & 4 & Likert 5-Point Scale & [40] \\
\hline & \multirow{2}{*}{$\begin{array}{l}\text { Operation System } \\
\text { Support System }\end{array}$} & $5-8$ & 4 & Likert 5-Point Scale & {$[6,42]$} \\
\hline & & $9-12$ & 4 & Likert 5-Point Scale & {$[14,30]$} \\
\hline \multirow{2}{*}{$\begin{array}{c}\text { Parameter } \\
\text { Dependent Variable }\end{array}$} & Value Creation & $13-16$ & 4 & Likert 5-Point Scale & [38] \\
\hline & Global Growth & $17-20$ & 4 & Likert 5-Point Scale & [13] \\
\hline \multirow[t]{2}{*}{ Demographic Factor } & \multirow[t]{2}{*}{$\begin{array}{c}\text { Gender, Age, Academic } \\
\text { Background, job, Global Entry }\end{array}$} & \multirow[t]{2}{*}{$1-6$} & 6 & Nominal Scale & \\
\hline & & & 26 & & \\
\hline
\end{tabular}

\subsubsection{Survey Target}

To examine the effects of system management on value creation and global growth in born startups, a survey was carried out to 350 domestic startup companies, as shown in Table 2 . It was finally targeted at 300 companies after excluding the final missing and non-responsive companies. 
Table 2. Survey target.

\begin{tabular}{cc}
\hline Classification & Content \\
\hline Target & Domestic startup companies \\
Personnel & 350 Companies (Use 300 Companies for Analysis) \\
Survey Period & $1-28$ February 2019 \\
Survey Method & Mail Survey or Visiting Survey \\
\hline
\end{tabular}

\subsubsection{Analysis Method}

The data collected in this study were analyzed using IBM SPSS statistic v.23.0 and analysis of moment structures (AMOS) 23.0, using a coding process, as follows. First, the frequency and percentage were calculated using frequency analysis to obtain statistical data on the general characteristics of those surveyed. Second, reliability analysis was conducted to verify the validity and reliability of the survey tool. Confirmatory factor analysis was performed on the measurement model to examine if the overall validity of the survey tool was supported by the AMOS program. Third, structural equation modeling was used to analyze the effects of system management on value creation and global growth in born startups.

\section{Results}

\subsection{Characteristics of Sample}

Frequency analysis was conducted to understand the demographic characteristics of those surveyed. The number of analyzed samples was 300, of which $67.7 \%$ and $32.3 \%$ were males and females, respectively. The results are shown in Table 3. The age majority was in the 30s or less (46.3\%). Regarding startup tendencies, the response rate of the 30 s or less was high at $75.7 \%$. For respondent jobs, office and technical occupations were the highest at $25.3 \%$, followed by sales at $24.3 \%$. Nearly $65.3 \%$ of respondents stated that their company had entered the global market and that more than $70 \%$ did so within three years after startup.

Table 3. Demographic characteristics of samples.

\begin{tabular}{|c|c|c|c|}
\hline \multicolumn{2}{|c|}{ Classification } & \multirow{2}{*}{$\begin{array}{c}\text { Frequency Number (Person) } \\
203\end{array}$} & \multirow{2}{*}{$\begin{array}{c}\text { Composition Ratio } \\
67.7 \%\end{array}$} \\
\hline & Male & & \\
\hline Gender & Female & 97 & $32.3 \%$ \\
\hline & Under 30s & 139 & $46.3 \%$ \\
\hline Age & $40 \mathrm{~s}$ & 88 & $29.3 \%$ \\
\hline \multirow{5}{*}{ Highest Level of Schooling } & Over 50 s & 73 & $24.3 \%$ \\
\hline & Under High School Graduation & 54 & $18.0 \%$ \\
\hline & Being in University & 75 & $25.0 \%$ \\
\hline & University Graduation & 141 & $47.0 \%$ \\
\hline & Over Graduate School & 30 & $10.0 \%$ \\
\hline \multirow{4}{*}{ Job } & Selling/Sales Service & 73 & $24.3 \%$ \\
\hline & Skill/Blue Collar & 59 & $19.7 \%$ \\
\hline & Office/Technical & 76 & $25.3 \%$ \\
\hline & Management/Administration & 50 & $16.7 \%$ \\
\hline \multirow{4}{*}{ Global Market Entry or No } & Free/Professional & 22 & $7.3 \%$ \\
\hline & Other & 20 & $6.7 \%$ \\
\hline & Entry & 196 & $65.3 \%$ \\
\hline & No & 104 & $34.7 \%$ \\
\hline \multirow{5}{*}{ Global Entry Time } & Simultaneously with Startup & 3 & $1.5 \%$ \\
\hline & Under 1 Year after Startup & 34 & $17.3 \%$ \\
\hline & 1 Year to 3 Years after Startup & 104 & $53.1 \%$ \\
\hline & 3 Years to 5 Years after Startup & 51 & $26.0 \%$ \\
\hline & 5 Years to 7 Years after Startup & 4 & $2.0 \%$ \\
\hline
\end{tabular}

\subsection{Exploratory Factor Analysis}

Reliability and validity analysis was conducted to confirm that the measurement tools were appropriate. The reliability analysis confirmed the possibility of obtaining the same values when 
repeated measurements were assumed for the research targets. Cronbach's alpha coefficient was used to verify the reliability of individual items. The closer to 1 , the higher the reliability is. In this study, the threshold was set at 0.7 , and it was judged that there was no problem with the reliability of the variable when the coefficient value was more than 0.7 [43].

Exploratory factor analysis explored the linkage of intrinsic factors in the observation variables to verify their validity by figuring out the structure between factors. The factor loadings of more than 0.5 were judged to be significant [44]. In this study, reliability analysis was conducted to verify the internal validity of the extracted components, for which Cronbach's alpha was more than 0.7, ensuring reliability. The results of exploratory factor analysis and reliability analysis are summarized in Tables 4 and 5 .

Table 4. Reliability analysis and exploratory factor analysis.

\begin{tabular}{|c|c|c|c|c|c|}
\hline & & \multicolumn{3}{|c|}{ Component } & \multirow{2}{*}{ Cronbach's Alpha } \\
\hline & & 1 & 2 & 3 & \\
\hline \multirow{4}{*}{ Entrepreneurship } & Global Orientation & 0.722 & & & \multirow{4}{*}{0.889} \\
\hline & Network Capability & 0.847 & & & \\
\hline & Owner's Expertise & 0.796 & & & \\
\hline & Capital Scale & 0.813 & & & \\
\hline \multirow{4}{*}{ Operation System } & Product Competitiveness & & 0.792 & & \multirow{4}{*}{0.868} \\
\hline & Marketing Capability & & 0.826 & & \\
\hline & Professional Human Resources & & 0.730 & & \\
\hline & System Operation Capability & & 0.740 & & \\
\hline \multirow{4}{*}{ Support System } & Commercialization Support & & & 0.877 & \multirow{4}{*}{0.852} \\
\hline & Operation Fund Support & & & 0.858 & \\
\hline & Technical Support & & & 0.673 & \\
\hline & Equipment Facility Support & & & 0.720 & \\
\hline
\end{tabular}

Table 5. Reliability analysis and exploratory factor analysis.

\begin{tabular}{llcccc}
\hline & & & Component & Cronbach's Alpha \\
& & $\mathbf{1}$ & $\mathbf{2}$ & $\mathbf{3}$ & \\
\hline \multirow{5}{*}{ Value Creation } & Value Creation 1 & 0.806 & & & \\
& Value Creation 2 & 0.884 & & & \\
& Value Creation 3 & 0.882 & & 0.938 & \\
& Value Creation 4 & & & 0.870 & \multirow{2}{*}{0.710} \\
& Global Growth 1 & & & \\
Global Growth & Global Growth 2 & & 0.852 & & \\
& Global Growth 3 & & 0.847 & & \\
& Global Growth 4 & 0.595 & & \\
\hline
\end{tabular}

The factor analysis of independent variables showed that the Kaiser-Meyer-Olkin (KMO) value was 0.871 , showing a slightly strong relationship. Bartlett's sphericity test showed that the approximate chi-squared value was 2276.772 and that the significance probability was 0.000 , less than the significance level of 0.05 , showing that the research model is appropriate. Additionally, the factor loadings showed that the questionnaire items should be grouped into three factors. The reliability analysis showed that the Cronbach alpha values of the reliability statistics were $0.889,0.868$, and 0.852 , more than the standard of 0.7 .

The factor analysis of dependent variables showed that the KMO value was 0.692, showing that there was a normal relationship between them. The Bartlett's sphericity test showed that the approximate chi-squared value was 2276.772 and that the significance probability was 0.000 , less than the significance level of 0.05 , showing that the research model was appropriate. Bartlett's sphericity test showed that the approximate chi-squared value was 1057.765 and that the significance probability was 0.000 , less than the significance level of 0.005 , showing that the research model was appropriate. Furthermore, the factor loadings showed that the questionnaire items should be grouped into three factors. However, this study needed two factors. Therefore, value creation and global growth factors 
were removed. The reliability analysis after removal showed that the Cronbach's alpha values of reliability statistics were 0.834 and 0.710 , more than the standard of 0.7 , showing that the reliability of all factors was appropriate.

\subsection{Model Appropriateness Evaluation}

In this study, confirmatory factor analysis was conducted using AMOS 25 for the measurement variables extracted by exploratory factor analysis. Unlike exploratory factor analysis, which is conducted for the exploratory purpose of figuring out the research direction in research that has not yet been systematized or established theoretically, confirmatory factor analysis conducts factor analysis by setting the relationship between variables in advance. When the value of conceptual reliability and the average variance extracted (AVE) is more than 0.70 and more than 0.5 , respectively, the reliability of the measured variables can be obtained. A common method to measure intensive validity is by using the AVE. An average AVE of more than 0.5 can suitably explain the variance. The conceptual reliability value of more than 0.70 and the AVE value of more than 0.5 can obtain good reliability of the measured variables [45].

The creation and the global growth factors, removed by exploratory factor analysis, were excluded. Table 6 shows that all variables were reliable because all factors satisfied the conceptual reliability $>0.7$ and AVE $>0.5$. Confirmatory factor analysis and the fit are shown in Table 7 . The chi-square was 871.031 , determined by the difference between the input covariance matrix and the estimated covariance matrix and the size of the sample. The significance probability was $p<0.001$, which did not satisfy the standard value. However, the chi-square fit index was sensitive to the size of the sample and the number of measurement variables, showing that it is not a big problem, given that it is difficult to meet the standard value when the size of the sample is large. Therefore, it is common to judge the fit with other fit indices. Other fit indices showed that the comparative fit index was greater than 0.9 , the Tucker-Lewis index was greater than 0.9 , and the root mean square error of approximation was less than 0.05 , making it acceptable (Figure 3).

Table 6. Conceptual reliability and average variance extracted.

\begin{tabular}{|c|c|c|c|c|c|}
\hline & Path & $\begin{array}{c}\text { Standardized } \\
\text { Estimate }\end{array}$ & $\begin{array}{c}\text { Measurement } \\
\text { Error }\end{array}$ & $\begin{array}{l}\text { Conceptual } \\
\text { Reliability }\end{array}$ & $\begin{array}{c}\text { Average Variance } \\
\text { Extracted (AVE) }\end{array}$ \\
\hline \multirow{4}{*}{ Entrepreneurship } & Global Orientation & 0.822 & 0.18 & \multirow{4}{*}{0.92} & \multirow{4}{*}{0.75} \\
\hline & Network Capability & 0.851 & 0.162 & & \\
\hline & Owner's Expertise & 0.854 & 0.216 & & \\
\hline & Capital Scale & 0.765 & 0.33 & & \\
\hline \multirow{4}{*}{$\begin{array}{l}\text { Operation } \\
\text { System }\end{array}$} & Product Competitiveness & 0.74 & 0.293 & \multirow{4}{*}{0.91} & \multirow{4}{*}{0.71} \\
\hline & Marketing Capability & 0.776 & 0.264 & & \\
\hline & Professional Human Resources & 0.825 & 0.232 & & \\
\hline & System Operation Capability & 0.809 & 0.229 & & \\
\hline \multirow{5}{*}{ Support System } & Commercialization Support & 0.859 & 0.187 & \multirow{5}{*}{0.90} & \multirow{5}{*}{0.70} \\
\hline & Operation Fund Support & 0.851 & 0.187 & & \\
\hline & Technical Support & 0.659 & 0.345 & & \\
\hline & Equipment Facility Support & 0.704 & 0.329 & & \\
\hline & Value Creation 1 & 0.697 & 0.373 & & \\
\hline \multirow{3}{*}{ Value Creation } & Value Creation 2 & 0.809 & 0.211 & \multirow[t]{2}{*}{0.88} & \multirow[t]{2}{*}{0.72} \\
\hline & Value Creation 3 & 0.886 & 0.163 & & \\
\hline & Global Growth 2 & 0.793 & 0.342 & \multirow{3}{*}{0.85} & \multirow{3}{*}{0.69} \\
\hline \multirow[t]{2}{*}{ Global Growth } & Global Growth 3 & 0.977 & 0.026 & & \\
\hline & Global Growth 4 & 0.318 & 0.381 & & \\
\hline
\end{tabular}

Table 7. Model fit.

\begin{tabular}{cccccc}
\hline Model & Chi-square & Degrees of freedom & CFI & TLI & RMSEA \\
\hline Default model & 871.031 & 160 & 0.908 & 0.972 & 0.042 \\
\hline \multicolumn{4}{c}{ CFI: comparative fit index; TLI: Tucker-Lewis index; RMSEA: root mean square error of approximation }
\end{tabular}




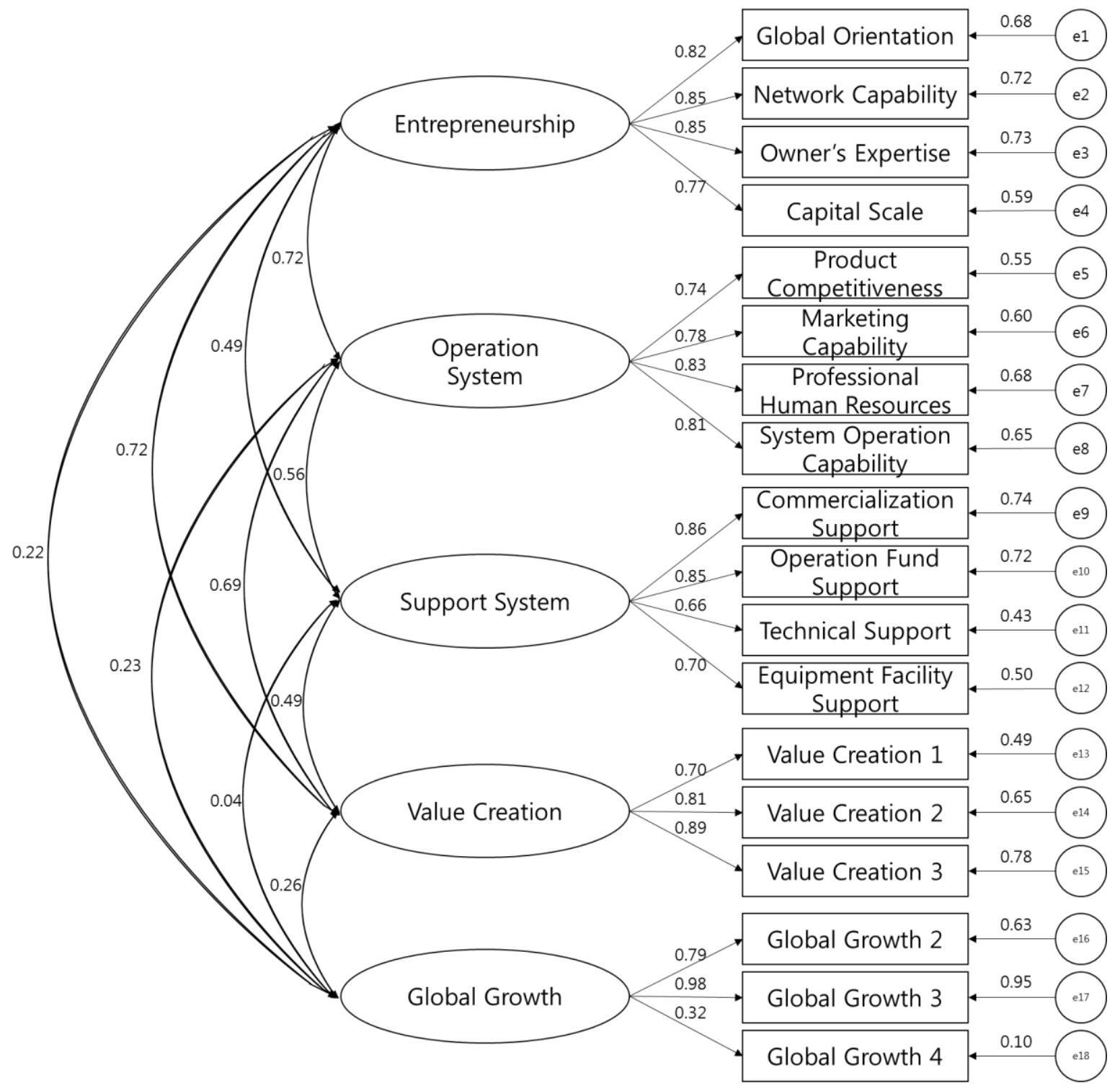

Figure 3. Confirmatory factor analysis.

In comparison with each AVE value and the correlation squared value between two constructs, there is discriminant validity if the AVE value is higher than the correlation squared value. The correlation squared value between all constructs is lower than each AVE value, as shown in Table 7, in which there is discriminant validity between all variables.

\subsection{Hypothesis Verification}

To verify each hypothesis, path analysis was conducted using the AMOS 25 program. This study adopted a significance level of $5 \%$. The discriminant validity of each construct is presented in Table 8 . The path analysis rejected the hypothesis that the support system affects value creation. $\mathrm{H} 4, \mathrm{H} 5$, and H7 are also rejected. All other hypotheses are adopted. The adoption or rejection of each hypothesis and the results of the path analysis are summarized in Table 9. In other words, entrepreneurship and operation systems have a positive effect on value creation, and the support system has a positive effect on global growth (Table 9). Figure 4 illustrates the result of the structural equation modeling analysis. 
Table 8. Discriminant validity of confirmatory factor analysis.

\begin{tabular}{cccc}
\hline Construct & Correlation Squared Value & AVE1 & AVE2 \\
\hline Entrepreneurship $\leftrightarrow$ Operation System & 0.525625 & 0.75 & 0.71 \\
Entrepreneurship $\leftrightarrow$ Support System & 0.237169 & 0.75 & 0.7 \\
Entrepreneurship $\leftrightarrow$ Value Creation & 0.512656 & 0.75 & 0.72 \\
Entrepreneurship $\leftrightarrow$ Global Growth & 0.049284 & 0.75 & 0.69 \\
Operation System $\leftrightarrow$ Support System & 0.311364 & 0.71 & 0.7 \\
Operation System $\leftrightarrow$ Value Creation & 0.471969 & 0.71 & 0.72 \\
Operation System $\leftrightarrow$ Global Growth & 0.0529 & 0.71 & 0.69 \\
Operation System $\leftrightarrow$ Value Creation & 0.243049 & 0.7 & 0.72 \\
Operation System $\leftrightarrow$ Global Growth & 0.001369 & 0.7 & 0.69 \\
Value Creation $\leftrightarrow$ Global Growth & 0.065536 & 0.72 & 0.69 \\
\hline
\end{tabular}

Table 9. Causal relationship measurement through path analysis.

\begin{tabular}{ccccccc}
\hline & B & $\boldsymbol{\beta}$ & S.E. & C.R. & P & Result \\
\hline Entrepreneurship $\rightarrow$ Value Creation & 0.442 & 0.385 & 0.074 & 5.173 & $* * *$ & Adoption \\
Operation System $\rightarrow$ Value Creation & 0.307 & 0.277 & 0.079 & 3.487 & $* * *$ & Adoption \\
Support System $\rightarrow$ Value Creation & 0.107 & 0.112 & 0.065 & 1.709 & 0.087 & Rejection \\
Entrepreneurship $\rightarrow$ Global Growth & 0.055 & 0.017 & 0.034 & 0.495 & 0.62 & Rejection \\
Operation System $\rightarrow$ Global Growth & 0.15 & 0.047 & 0.037 & 1.291 & 0.197 & Rejection \\
Support System $\rightarrow$ Global Growth & -0.171 & -0.062 & 0.031 & -1.992 & $0.046 *$ & Adoption \\
Value Creation $\rightarrow$ Global Growth & 0.198 & 0.069 & 0.04 & 1.742 & 0.082 & Rejection \\
\hline
\end{tabular}

${ }^{*} \mathrm{P} \leq 0.05 ;{ }^{* * *} \mathrm{P} \leq 0.001$.

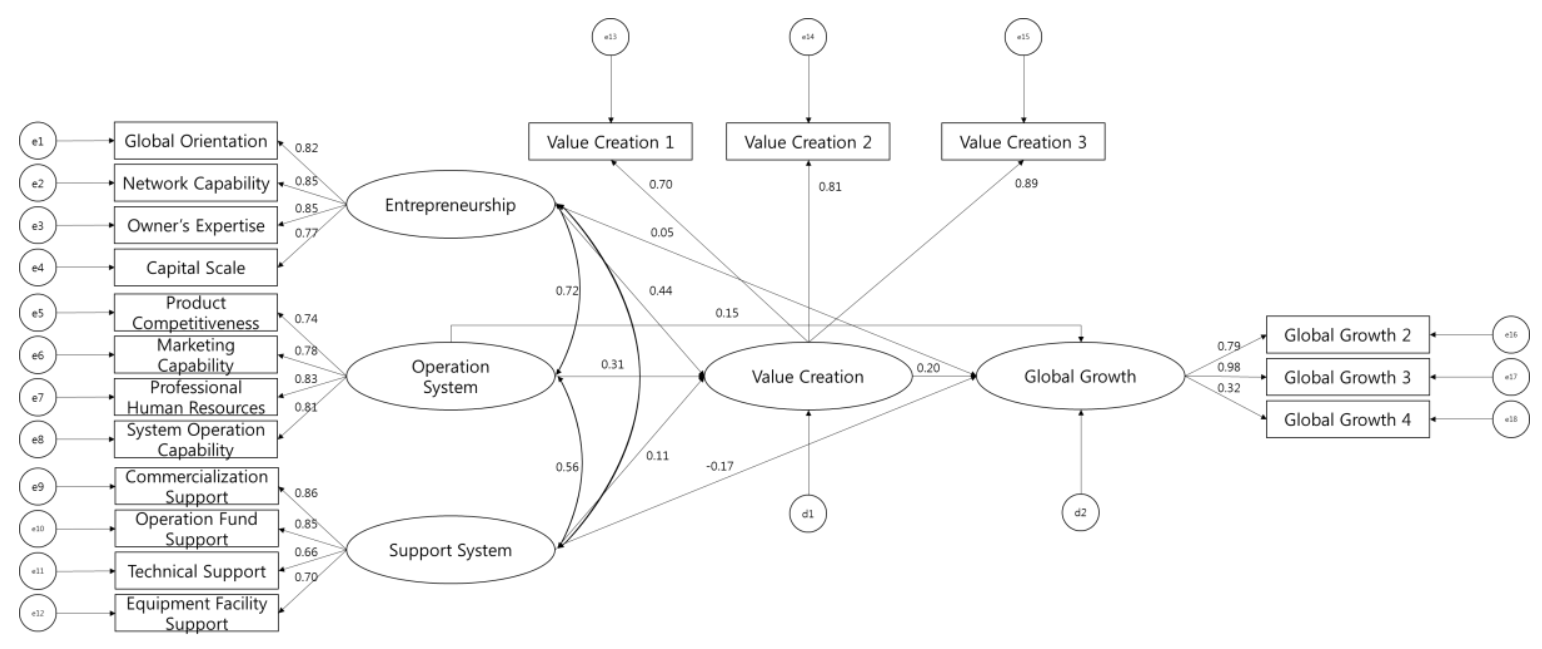

Figure 4. Result of structural equation modeling analysis.

\section{Discussion}

Overall, in terms of the effects of system management on value creation and global growth in born startups, entrepreneurship and operation system were adopted with a significant effect on value creation and global growth, while support system was rejected with no significant effect on value creation and global growth. These results are summarized as follows. First, the owner's globally-oriented management attitude, global network organization capability, expertise, and capital strength as entrepreneurship can boost value creation and global growth. Second, product competitiveness, marketing capability, professional human resources, and system operating capability as sub-factors of the operation system are mechanisms that have a positive effect on value creation and global growth. Third, the effect of the rejected support system on value creation and global growth demonstrates that network or global management is only derived when the specialized entrepreneurship and the 
organizational structure and operation, rather than having a direct effect, have system competitiveness for operation as a global startup, which can maximize its capability, leading to value creation in early stages to contribute to the stabilization of a born startup. This is a reminder that it is difficult to reach a short-term startup without the infrastructure and expertise as a competitive base in the face of accelerating the globalization of global venture companies.

As a result, the born startup is a driving force for rapid growth based on high technology and economy of scale for early growth.

In particular, unicorns such as Uber, Airbnb, and Xiaomi are born startups, leading the fastest-growing high-tech sectors such as e-commerce, and Internet software and service. The global private investment in born startups grew 3.6 times from USD 45.3 billion in 2012 to USD 164.4 billion in 2017, proving the growth force through the high value of global orientation and capital scale. [10]

Global competitiveness is ultimately dependent on technology-based business models, suggesting that organizations and product technologies must be backed up to realize high growth and high profits in the fourth industrial revolution era.

Overall, for the strategic competitive edge through business alliances and the development of new businesses and new technologies in competition with large companies, startups must consistently discover the growth engine through win-win innovation such as open innovation activities of large companies and technological exchanges between startups, and need to form partnerships to continue and expand alliances through complementary collaborations in opening up a market for marketing and distribution.

Moreover, they must continue to innovate their own capability as institutional complementation as well as win-win cooperation to improve technological competitiveness and make institutional efforts for preventing business model and technology fraud, using market status to achieve true win-win innovation at the same time.

Finally, this study has a limit of generalizing the overall results, in that a survey was carried out to some domestic limited companies, and follow-up studies should be carried out with even samples by adding factors that are not reflected in this study in the future.

Author Contributions: R.L. and J.G.P. conceived and designed the research; S.H.P. collected and analyzed the data; R.L. and J.G.P. wrote the paper. All authors have read and agreed to the published version of the manuscript.

Funding: This research received no external funding.

Conflicts of Interest: The authors declare no conflict of interest.

\section{References}

1. Tae-kyung, P.; In, J. Internationalization of Born Globals and Its Determinants: A Case Study; Korean Association of Small Business Studies: Seoul, 2011.05.31. J. Entrep. Ventur. Stud. 2011, 14, 71-89.

2. Karson, E.; Gascon, C.S. Growth in Tech Sector Returns to Glory Days of the 1990s; The Regional Economist, Federal Reserve Bank: St. Louis, MO, USA, 2017; Volume 25.

3. Jaegars, T.; Lipp-Lingua, C.; Amil, D. High-Technology and Medium-High Technology Industries Main Drivers of EU-27's Industrial Growth. Eurostat Statistics in Focus. 2013. Available online: http://gesd.free.fr/ ks13001.pdf (accessed on 1 March 2020).

4. Decker, R.; Haltiwanger, J.; Jarmin, R.; Miranda, J. The Role of Entrepreneurship in US Job Creation and Economic Dynamism. J. Econ. Perspect 2014, 28, 3-24. [CrossRef]

5. Marwick, A. Silicon Valley and the social media industry. In Sage Handbook of Social Media; Sage: London, UK, 2017.

6. Moen, W.E. Assessing interoperability in the networked environment: Standards, evaluation, and testbeds in the context of Z39. 50. Am. Soc. Inf. Sci. 2001, 38, 669-670.

7. Joon-soo, P. Proposals to Improve Government Funding of Domestic Start-Up Businesses through Living Lab: Focus on Korea Credit Guarantee Fund. J. Converg. Inf. Technol. 2018, 8, 301-312.

8. Lee, J.W. Asia's largest startup conference: Echelon Asia Summit 2017. Sci. Technol. Policy 2017, 27, 66-69. 
9. Kuivalainen, O.; Lindqvist, J.; Sami Saarenketo, T. International Growth of Finnish Software Firms Starting Points, Pathways and Outcomes. J. Euromarketing 2007, 16, 7-22. [CrossRef]

10. Jim, K. Another Damn Thing We've Got to Do: Teacher Perceptions of Professional Development; Educational Resources Information Center: Springfield, MO, USA, 2001.

11. Oviatt, B.M.; McDougall, P.P. Toward a Theory of International New Ventures. J. Int. Bus. Stud. 1994, 25, 45-64. [CrossRef]

12. Genome, S. Global Startup Ecosystem Report 2017; Startupgenome: San Francisco, CA, USA, 2017; p. 9.

13. Moon, B.K.; Kim, K.W.; Jung, K.I.; Kang, N.Y.; Lee, J.H.; You, S.K. (First Six Months of 2018) Import \& Export Assessment and the Second Half Outlook. In (IIT) Under Korea International Trade Association, Electronic Data; Korean Institute for International Trade: Seoul, Korea, 2018.

14. Nam, D.H. The Present of Korea Startups from Global Perspective; Trade Policy Support Center Under Korea International Trade Association: Seoul, Korea, 2018.

15. Kim, B.K. Startup Trend and Its Implications from Unicorn; Korean Institute for International Trade: Seoul, Korea, 2017; pp. 1-8.

16. Colombo, M.G.; D'Adda, D.; PIVA, E. The contribution of university research to the growth of academic start-ups: An empirical analysis. J. Technol. Transf. 2010, 35, 113-140. [CrossRef]

17. Lim, J.W. The Status and Tasks of Korean Startup Ecosystems. J. Korea Inf. Sci. Soc. 2015, 33, 19-25.

18. Kim, B.; Kim, H.; Jeon, Y. Critical success factors of a design startup business. Sustainability 2018, 10, 2981. [CrossRef]

19. Park, J.H. A Study on the Policy Trends and Cooperative Measures for Establishment and Startup Incubation in Emerging Areas; Korea Information Society Development Institute: Seoul, Korea, 2018.

20. Schumpeter, J.A. The Theory of Economic Development: An Inquiry into Profits, Capital, Credit, Interest, and the Business Cycle; Translated from the German by R. Opie; Harvard University Press: Cambridge, MA, USA, 1934.

21. Lee, C.W. A Organizational Life Cycle Model for Small Business Resource Management with Resource-Based View Criticised. Small Bus. Rev. 2009, 31, 51-71.

22. Lee, S.B. A Study on Obstacle Factors of Global Start-Up Promotion. J. Acad. Ind. Technol. 2019, $20,338-352$.

23. Korea, S. Report, Google Campus; Asan Nanum Foundation: Seoul, Korea, 2018.

24. Zahra, T. Did Buffy Do It? Nation 1999, 269, 11.

25. Türker, L.; Gümüs, S.; Atalar, T. Structural and Molecular Orbital Properties of Some Boroxine Derivatives: A Theoretical Study. Bull. Korean Chem. Soc. 2009, 30, 2233-2239.

26. Dae-yong, C.; Bong-ho, Y. An Empirical Study on the Effects of Entrepreneurial Orientation \& Market Orientation to the Organizational Effectiveness and Business Performance. Korean Ventur. Manag. Rev. 2007, 31, 69-93.

27. Samiee, S. International Market-Entry Mode Decisions: Cultural Distance's Role in Classifying Partnerships Versus Sole Ownership. J. Bus. Res. 2013, 66, 659-661. [CrossRef]

28. Johnson, B.R. Toward a Multidimensional Model of Entrepreneurship: The Case of Achievement Motivation the Entrepreneur. Entrep. Theory Pract. 1990, 14, 39-54. [CrossRef]

29. Seung-bae, L. The Effect of Individual Characteristics and Environmental Factors on College Students' Entrepreneurial Intentions: Mediating Role of Entrepreneurship Education, Daegu. Manag. Educ. 2016, 31, 117-138.

30. North, D.C. Understanding the Process of Economic Change; Princeton University Press: Princeton, NJ, USA, 2005.

31. Silverman, B.S.; Ingram, P. (Eds.) The New Institutionalism in Strategic Management; JAI Press: Amsterdam, The Netherland, 2002.

32. PwC, C.B. Insight; MoneyTree Report Q4 2017. Available online: https://keiretsuforum-midatlantic.com/wpcontent/uploads/2016/12/cb-insights_moneytree-q4-2017.pdf (accessed on 1 March 2020).

33. Law, R. The Startup Funding Bible: How to Raise Money Like a Unicorn. 2017. Available online: https://www.cobloom.com/blog/startup-funding?utm_campaign=Submission\&utm_medium= Community\&utm_source=GrowthHackers.com (accessed on 1 March 2020).

34. Romney, G.W.; Guymon, J.; Romney, M.D.; Carlson, D.A. Curriculum for Hands-on Artificial Intelligence Cybersecurity. In Proceedings of the 2019 18th International Conference on Information Technology Based Higher Education and Training (ITHET), Magdeburg, Germany, 26-27 September 2019; pp. 1-8. 
35. Lee, K.Y.; Kwon, H.Y.; Lim, J.I. Legal consideration on the use of artificial intelligence technology and self-regulation in financial sector: Focused on robo-advisors. In International Workshop on Information Security Applications; Springer: Cham, Switzerland, 2017; pp. 323-335.

36. Forbes. The Forbes 400; Forbes: New York, NY, USA, 2017; Volume 200, pp. 86-167.

37. Haltiwanger, J.; Hathaway, I.; Miranda, J. Declining Business Dynamism in the U.S. High-Technology Sector. SSRN 2397310 2014. [CrossRef]

38. Moretti, E. Real Wage Inequality. Am. Econ. J. Appl. Econ. 2013, 5, 65-103. [CrossRef]

39. Jantunen, A.; Nummela, N.; Puumalainen, K.; Saarenketo, S. Strategic Orientations of Born Globals: Do They Really Matter? J. World Bus. 2008, 43, 158-170. [CrossRef]

40. Byung-oh, K. A Study on the Influence of CEOs' Entrepreneurship on Corporate Performance in SMEs: Focusing on Franchise Companies. Ph.D. Thesis, ChungAng University Graduate School, Seoul, Korea, 2011.

41. Je-hyun, P. A Comparative Study on Korean and Chinese Corporate Merger System: Legal Analysis from the Perspective of Antitrust Law; Renmin University of China: Beijing, China, 2007.

42. Yoo, J.H. New Product Development Strategy in Early Startup: Focused on Hardware Startups. Master's Thesis, Kumoh National Institute of Technology, Gumi, Korea, 2018.

43. Hair, J.F.; Black, W.C.; Babin, B.J.; Anderson, R.E.; Tatham, R.L. Multivariate Data Analysis; Prentice Hall: Upper Saddle River, NJ, USA, 1998.

44. Hoon-young, L. Professor Lee Hoon-young's Data Analysis Using SPSS; Cheongram: Seoul, Korea, 2013.

45. Fornell, C.; Larcker, D.F. Evaluating Structural Evaluation Models with Unobservable Variables and Measurement Error. J. Mark. Res. 1981, 18, 39-50. [CrossRef]

(C) 2020 by the authors. Licensee MDPI, Basel, Switzerland. This article is an open access article distributed under the terms and conditions of the Creative Commons Attribution (CC BY) license (http://creativecommons.org/licenses/by/4.0/). 